\title{
Development of $3 \beta$-hydroxysteroid dehydrogenase in the ovary of the domestic fowl during sexual maturation
}

\author{
D. G. Armstrong and J. W. Wells \\ Agricultural Research Council's Poultry Research Centre, King's Buildings, West Mains Road, \\ Edinburgh EH9 3JS, U.K.
}

The enzyme complex $\Delta^{5}$-3 $\beta$-hydroxysteroid dehydrogenase (EC 1.1.1.51)- $\Delta^{5}$-3-oxosteroid isomerase (EC 5.3.3.1) catalyses the conversion of pregnenolone to progesterone and dehydroepiandrosterone to androst-4-ene-3,17-dione in tissue producing steroid hormones. A recent study demonstrated that this enzyme complex ( $3 \beta-H S D)$ in the ovary of the domestic fowl is distributed predominantly in the microsomal fraction, and there were marked quantitative and qualitative differences in the $3 \beta$-HSD obtained from the ovaries of immature pullets compared with that from laying hens (Armstrong \& Wells, 1976).

We report on the results of a study of the development of $3 \beta-H S D$ activity in the ovaries of pullets from 13 to 22 weeks of age.

The 29 birds used in this study were bred from a commercial strain of medium-weight layers, Shaver 288 type. Ovaries and oviducts were obtained from groups of birds killed at weekly intervals. The preparation of microsomal fractions from ovarian homogenates and radioactive enzymatic assays for $3 \beta$-HSD have been described previously (Armstrong \& Wells, 1976). The kinetic parameters, $V_{\max }$ and $K_{m}$ (with respect to NAD ${ }^{+}$), of microsomes were derived from double reciprocal plots of the rates of conversion of $\left[4{ }^{14} \mathrm{C}\right]$ pregnenolone to progesterone obtained at 5 different concentrations of $\mathrm{NAD}^{+}$(each duplicated). Microsomal protein and RNA were measured by the methods of Lowry, Rosebrough, Farr \& Randall (1951) and Schneider (1957), respectively. Weekly blood samples from the surviving birds were tested for low-density lipoprotein (LDLP) by diluting fresh blood plasma $(100 \mu \mathrm{l})$ with distilled water $(1 \mathrm{ml})$ and observing whether or not the precipitation of the characteristic flocs occurred (McIndoe, 1959).

As found by Amin \& Gilbert (1970), the weights of the ovary and oviduct changed during the period from 13 to 22 weeks of age; the mean ovarian weight increased from $0.32 \mathrm{~g}$ at 13 weeks of age to $4.53 \mathrm{~g}$ (excluding the contents of the larger follicles) at 22 weeks, about a 14-fold change, and the oviduct weight increased 181 times during the same period.

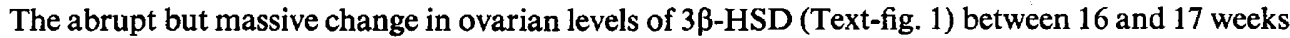
was highly significant $(P<0.001)$ whether enzyme activity, calculated from the $V_{\max }$, values, was expressed as $\mathrm{nmol} / \mathrm{min}$ per ovary (increase: $8 \cdot 7$-fold) or as specific activity in $\mathrm{nmol} / \mathrm{min}$ per $\mathrm{g}$ ovary (increase: $8 \cdot 5$-fold). Before 17 weeks the mean \pm S.E.M. activity was low but appreciable at 0.76 $\pm 0.09 \mathrm{nmol} / \mathrm{min}$ per ovary $(\mathrm{N}=11$; birds aged between 13 and 16 weeks).

In an earlier histological study Deol (1955) observed dramatic changes in the cytoplasm of ovarian medullary cells which changed from a glossy clear to a granular appearance at 17 weeks of age. About this time new cells filled with large spherical eosinophilic granules appeared in the theca externa of the follicles. We found that the microsomal protein showed the largest increase, about 3-fold, at 17 weeks whereas the RNA content of the microsomal fraction (assumed to be ribosomal RNA) rose continuously from $87 \mu \mathrm{g}$ at 15 to $270 \mu \mathrm{g}$ at 18 weeks of age.

The avian oviduct is a very sensitive indicator of the levels of circulating steroid hormones (Gilbert, 1967). Since the oviducts of the birds examined here showed massive weight changes after 17 weeks, i.e. a week later than the largest rise in ovarian $3 \beta-H S D$, this period must be one of increased steroid secretion. It coincided with the appearance of small white follicles ( 1 to $2 \mathrm{~mm}$ diam.) in the ovary and with the characteristic reddening of the comb (Sharp, 1975) which occurs before enhanced comb growth commences.

A later indicator of increased oestrogen secretion is the appearance of LDLP in blood plasma which is detected shortly before egg-laying commences (McIndoe, 1959), corresponding with the 


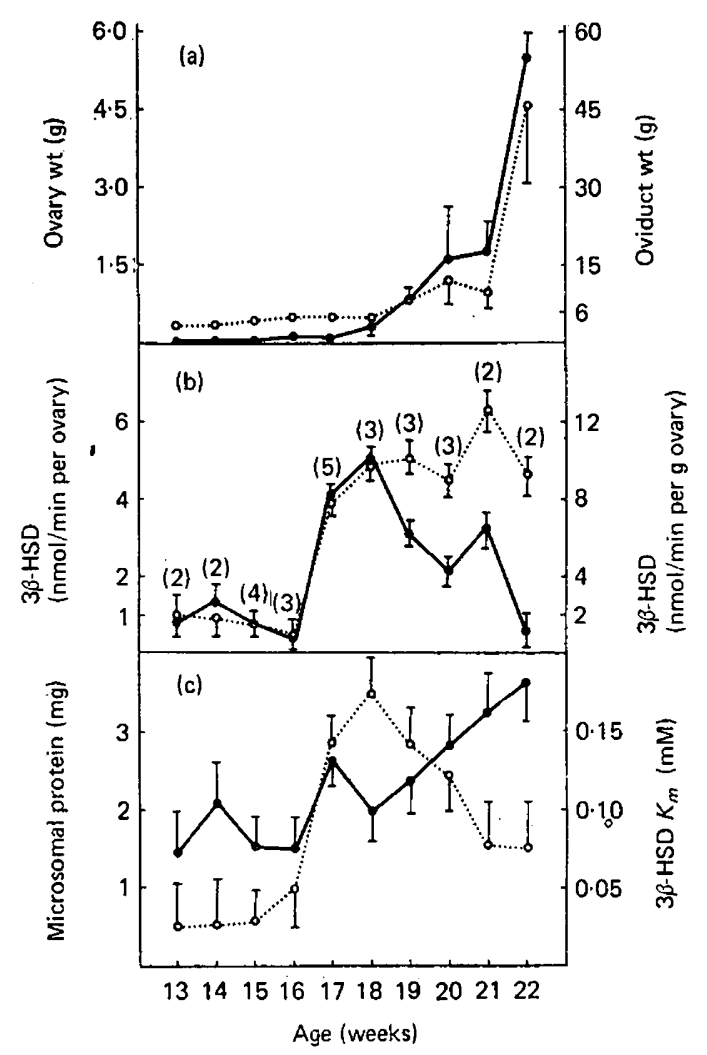

Text-fig. 1. Comparison of the changes in organ weights with enzyme parameters during sexual maturation of pullets: (a) ovarian $(O)$ and oviducal weight $(\bullet)$; (b) $3 \beta$-HSD activity expressed as nmol/min per ovary $(O)$ or as $\mathrm{nmol} / \mathrm{min}$ per $\mathrm{g}$ ovary $(\bullet)$; (c) protein content of microsomal fraction $(O)$ in which $3 \beta$-HSD activity and $3 \beta$-HSD $K_{m}$ values (with respect to co-factor $\left.\mathrm{NAD}^{+}\right)(\bullet)$ were measured. Values are means with S.E.M. The numbers of animals used each week are indicated by the numbers in parentheses in (b).

development of yellow yolky follicles. At 19 weeks, only 2 out of 15 birds gave positive tests for LDLP compared with 5 out of 9 birds at 22 weeks of age. These observations agree with the analytical results of Senior (1974) who found a significant rise in plasma oestrogens 5 weeks before the onset of egg-laying (corresponding to 18 weeks of age in the birds used in this study) culminating in a peak of secretion 2 weeks later.

The other kinetic parameter of enzymatic activity, $K_{m}$ (with respect to $\mathrm{NAD}^{+}$), changed more slowly. By 22 weeks of age the $K_{m}$ values for ovarian $3 \beta$-HSD had not yet reached the values $(0.30$ to $0.45 \mathrm{~mm}$ ) characteristic of the laying hen (Armstrong \& Wells, 1976). These differences are attributed to the absence of the large yellow yolky follicles which are typical of the ovary of the laying hen.

We suggest that the changes in ovarian 3 $\beta$-HSD activity observed in hens between 16 and 17 weeks of age are triggered by increased secretion of gonadotrophins, particularly LH. In maturing pullets at about this time Sharp (1975) observed the beginning of a prepubertal peak of LH which lasted 2-3 weeks. During sexual maturation of the fowl the curve for microsomal protein in the ovary parallels that for enzyme activity expressed as nmol/min per $g$ ovary (Text-fig. 1), indicating that there is an increase in the amount of active tissue as there is in the rat. Immature rats treated with gonadotrophins responded with an increase in the total activity of ovarian 33-HSD without changes in specific activity (Rubin \& Deane, 1965).

The observations recorded here emphasize one of the early changes in ovarian enzymology in the sexually maturing pullet. Since $3 \beta-H S D$ is a key enzyme in the biosynthesis of $C_{21}, C_{19}$ and $C_{18}$ steroid hormones, the increase in $3 \beta-H S D$ activity in the ovary of the pullet after 16 weeks of age is 
an essential preliminary for subsequent hormonal secretion. These steroid hormones in turn induce growth of the oviduct and hepatic synthesis of various lipoproteins which become incorporated into the ovum.

\section{References}

Amin, S.O. \& GilberT, A.B. (1970) Cellular changes in the anterior pituitary of the domestic fowl during growth, sexual maturity and laying. Br. Poult. Sci. 11, 451-458.

Armstrong, D.G. \& Wells, J.W. (1976) The measurement of $3 \beta$-hydroxysteroid dehydrogenase in ovaries of fowls (Gallus domesticus). Gen. comp. Endocr. (in press).

DEOL, G.S. (1955) Studies on structure and function of the ovary of the domestic fowl (with reference to the correlation of cell changes with physiological activity). Ph.D. thesis, University of Edinburgh.

GilBERT, A.B. (1967) Formation of the egg in the domestic chicken. Adv. Reprod. Physiol. 2, 111-180.

Lowry, O.H., Rosebrough, N.J., FARR, A.L. \& RANDALL, R.J. (1951) Protein measurement with the Folin phenol reagent. J. biol. Chem. 193, 265-275.

McINDOE, W.M. (1959) A lipophosphoprotein complex in hen plasma associated with yolk production. Biochem. J. 72, 153-159.

Rubin, B.L. \& DEANE, H.W. (1965) Effects of superovulation on ovarian $\Delta^{5}-3 \beta$-hydroxysteroid dehydrogenase in rats of different ages. Endocrinology 76, 382-389.

SCHNEIDER, W.C. (1957) Determination of nucleic acids in tissues by pentose analysis. In Methods in Enzymology, Vol. 3, pp. 680-684. Eds S. P. Colowick \& N. O. Kaplan. Academic Press, New York.

SENIOR, B.E. (1974) Oestradiol concentration in the peripheral plasma of the domestic hen from 7 weeks of age until the time of sexual maturity. J. Reprod. Fert. 41, 107-112.

ShARP, P.J. (1975) A comparison of variations in plasma luteinising hormone concentration in male and female domestic chickens (Gallus domesticus) from hatch to sexual maturity. $J$. Endocr. 67, 211-223.

Received 2 April 1976 